\title{
DESIGN OPTIMAL CONTROL OF SHIP MANEUVER PATTERNS FOR COLLISION AVOIDANCE: A REVIEW
}

Chia-Hung Shih

Kobe University Graduate School of Science and Technology, Kobe University, 5-1-1 Fukae-minamimachi, Higashinada-ku, Kobe 658-0022, Japan. Department and Graduate School of Computer Science, National Pingtung University of Education, No. 4-18, Ming Shen Rd., Pingtung 90003, Taiwan

Po-Hsuan Huang Department of Computer Science and Information Engineering, National Central University, No. 300, Jhongda Rd., Jhongli City, Taoyuan County 32001, Taiwan

\section{Saburo Yamamura}

Kobe University Graduate School of Science and Technology, Kobe University, 5-1-1 Fukae-minamimachi, Higashinada-ku, Kobe 658-0022, Japan

\section{Chen-Yuan Chen}

Department and Graduate School of Computer Science, National Pingtung University of Education, No. 4-18, Ming Shen Rd., Pingtung 90003, Taiwan Department of Information Management, National Kaohsiung First University of Science and Technology, Kaohsiung, Taiwan. Global Earth Observation and Data Analysis Center (GEODAC), National Cheng Kung University, No. 1, Ta-Hsueh Road, Tainan 701, Taiwan

Follow this and additional works at: https://jmstt.ntou.edu.tw/journal

Part of the Engineering Commons

\section{Recommended Citation}

Shih, Chia-Hung; Huang, Po-Hsuan; Yamamura, Saburo; and Chen, Chen-Yuan (2012) "DESIGN OPTIMAL CONTROL OF SHIP MANEUVER PATTERNS FOR COLLISION AVOIDANCE: A REVIEW," Journal of Marine Science and Technology.

Vol. 20: Iss. 2, Article 1.

DOI: $10.51400 / 2709-6998.1829$

Available at: https://jmstt.ntou.edu.tw/journal/vol20/iss2/1

This Research Article is brought to you for free and open access by Journal of Marine Science and Technology. It has been accepted for inclusion in Journal of Marine Science and Technology by an authorized editor of Journal of Marine Science and Technology. 


\section{DESIGN OPTIMAL CONTROL OF SHIP MANEUVER PATTERNS FOR COLLISION AVOIDANCE: A REVIEW}

\section{Acknowledgements}

The authors are appreciative of the financial support in the form of research grants to Dr. Chen-Yuan Chen from the National Science Council, Republic of China under Grant Nos. NSC 99-2628-E153-001 and NSC 100-2628-E153-001. The authors also wish to voice his appreciation for the kind assistance of Professor Chein-Shan Liu, Editor of the Journal of Marine Science and Technology, and would also like to thank the anonymous reviewers for their constructive suggestions which have greatly aided in the improvement of this paper 


\title{
DESIGN OPTIMAL CONTROL OF SHIP MANEUVER PATTERNS FOR COLLISION AVOIDANCE: A REVIEW
}

\author{
Chia-Hung Shih ${ }^{1,2}$, Po-Hsuan Huang ${ }^{3}$, Saburo Yamamura ${ }^{1}$, and Chen-Yuan Chen ${ }^{2,4,5}$
}

Key words: optimal turning maneuver, control model, ship transportation.

\begin{abstract}
Although there have been lots studies about vehicular maneuvers on land or sea, maneuvers within a small area that require direction changes have rarely been discussed. Many reports on the arrival or departure of ships from ports have revealed more about what are safe and effective turning maneuvers within a narrow area. Convenient navigation systems for ship maneuvering should allow quick avoidance of obstacle to find the shortest distance in the whole seaway is important. This study proposes a review model that will satisfy optimal turning maneuvering anywhere and be applicable to any type of ship. However, the water-based environment is more complex and there are many factors that will affect the formula. By using a nonlinear unified state-space model to discuss another model we can divide and conquer the problem. In recent studies some categories have been evaluated to determine where the main attention should be directed. In this review study we look at how to construct the optimal turning maneuver within a limited sea area.
\end{abstract}

\section{INTRODUCTION}

Water-based transportation is more complex than landbased transportation and there are various environmental factors and vessel characteristics that should be considered in

Paper submitted 12/17/09; revised 05/19/10; accepted 06/20/10. Author for correspondence: Chen-Yuan Chen (e-mail: cyc@mail.npue.edu.tw).

Kobe University Graduate School of Science and Technology, Kobe University, 5-1-1 Fukae-minamimachi, Higashinada-ku, Kobe 658-0022, Japan.

${ }^{2}$ Department and Graduate School of Computer Science, National Pingtung University of Education, No. 4-18, Ming Shen Rd., Pingtung 90003, Taiwan. ${ }^{3}$ Department of Computer Science and Information Engineering, National Central University, No. 300, Jhongda Rd., Jhongli City, Taoyuan County 32001, Taiwan.

${ }^{4}$ Department of Information Management, National Kaohsiung First University of Science and Technology, Kaohsiung, Taiwan.

${ }^{5}$ Global Earth Observation and Data Analysis Center (GEODAC), National Cheng Kung University, No. 1, Ta-Hsueh Road, Tainan 701, Taiwan. the control of ships for maneuvers. There have been lots studies about structure control in the natural physics $[2,4$, 13-67, 68-83, 97-103, 105, 108-111, 113-134, 136, 137]. Nevertheless, a unified numerical model for ship maneuvers is difficult to establish, because the factors affecting it (as described above) are normally nonlinear [157, 158, 197-231].

Ships are of various types designed according to their purpose. The ship's length, weight and even appearance, and the power of its rudders and thrusters, all have a significant effect on the characteristics of its maneuverability [159, 163177, 179-187, 192, 193]. Due to these conditions, even if a numerical model can be established, it would be difficult to apply to all types of ships. In previous research studies it is common to give restrictions when discussing particular issues about a specific ship. However, it is still necessary to define the basic conditions of an objective ship type. Most models cannot be applied to all types of ships.

In this paper we will discuss several different levels that are related to the behavior of ships. These three levels introduce optimal ship maneuvering, for instance ship positioning, optimal path of ship maneuvering and inland ship maneuvering.

\section{LITERATURE REVIEW}

\section{Ship Positioning}

There are different ways to control a ship's yaw. The basic system uses a single rudder or twin rudders at the stern, operating in conjunction. Of course, there are more advanced system, for example, to use twin tunnel thrusters, one installed on the bow section and on the stern, which offers transversal thrust. A contemporary ship might use one or several systems operating in conjunction, for instance, the Glomar Explorer deep-sea mining ship in 1974 and the Glomar C. R. built Luigs drillship in 1999.

Obviously, from prior definition, the control system finds optimal control of ship maneuvers. Therefore, we focus on the basic system which is based on having a single rudder located at the stern to control the ship [140, 147, 148, 150]. Various methods for the study of ship maneuvering have been studied [5, 68, 107, 194]. For more details about ship control modeling see: Inoue, Hirano, Kijima and Takashina [104]; Barr 
Table 1. Four sub problems of the Mayer problem.

\begin{tabular}{|c|c|c|}
\hline & Problem description & Quasi-steady state \\
\hline P1 & \multirow{2}{*}{ Change the yaw angle by a given amount } & Not required \\
\cline { 3 - 3 } P2 & Required \\
\hline P3 & Bring the ship from a given initial course & Not required \\
\cline { 1 - 1 } P4 & to a parallel course & Required \\
\hline
\end{tabular}

[9], Fossen [86] and Mandel [135]. For more on the theme of optimal ship maneuvering see: Amerongen and Lemke [3]; Miloh and Pachter [153]; Teo and Lim [178]; Tzeng [189]; Yavin, Francos, Miloh and Zilman [196]; Yavin, Francos and Miloh [195]. In particular, see Tseng [189] and the work of Yavin et al. for discussion in either a deterministic setting or a stochastic setting with the boundary conditions handled via penalty function techniques [194-196].

In this type of problem, when describing the ship's movement, we calculate the center of ship which is a fixed point ship, rather than the center of gravity, because this is a variable point. A more complete set of equations is needed to describe the motion of the ship, so as to enable one to consider the restriction of complex boundary conditions without adapting to penalty function techniques. Actually, having a new transformation technique allows one to avoid singularities at the upper and lower bounds of the rudder angle when it and its time derivative incur symmetric upper and lower bounds. Hence, two problems are considered that is course change maneuvers and sidestep maneuvers. The restriction is that the ship must initially be in a quasi-steady state. The criteria for optimization of course change maneuvers and sidestep maneuvers are studied as Mayer problems of optimal control. There are a total of four problems that need to be solved in Table 1.

Constraint: the yaw angle time rate vanishes at the final point.

The sequential gradient-restoration algorithm (SGRA) developed by Miele et al. during the years 1968 to 1986 is used to solve the above problems [91, 138, 139, 144, 145, 146]. This first-order algorithm has proven to be a powerful method to improve trajectory tracking problems in the following situations:

- Flight in windshear [149]

- National aerospace plane [145]

- Aeroassisted orbital transfer [152]

- Interplanetary flight [161]

- Next-generation orbital spacecraft [141]

SGRA has been used to calculate variations/optimal control in the Bolza problem. The Lagrange and Mayer problems are special cases of the Bolza problem. Since they are Mayer-type problems, the SGRA can deal with Problems P1 to P4 (in a minimum time).

In 1999, Miele, Wang, Chao and Dabney used the sequential gradient-restoration algorithm to formulate and solve

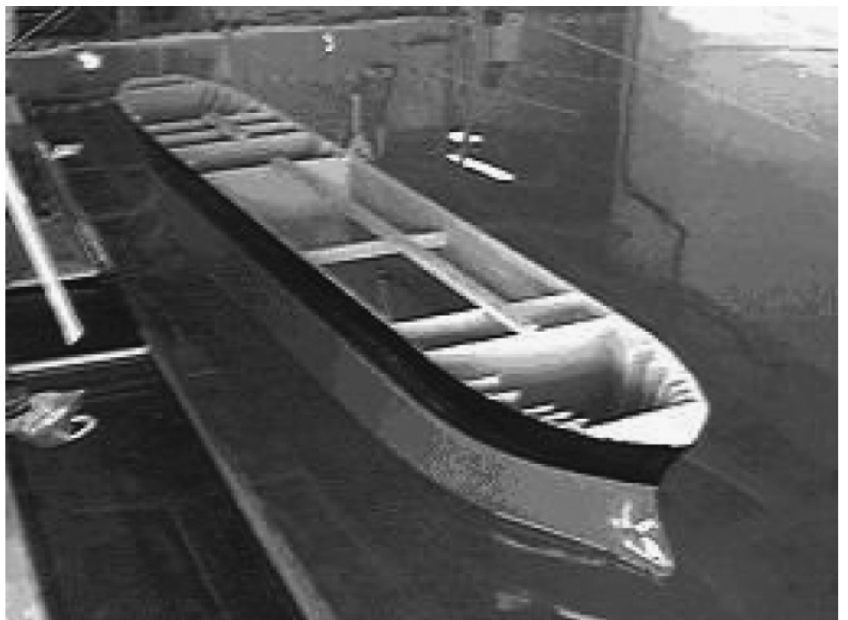

Fig. 1. The "Esso Osaka” model ship [156].

Mayer problems of optimal control [151]. They assumed the criterion of optimization to be the minimum time. The final goal of this method is correctly calculate the module which is significant for improving control of ship maneuvers in a particular situation.

\section{Optimal Path of Ship Maneuvers}

Both surface and underwater ships are used for monitoring of coastal and inland waters monitoring. Especially, the use of autonomous marine vehicles has grown significantly in recent years, partly due to their low cost, and partly due to their application of autonomous guidance and control technologies that can accomplish tasks by themselves.

There is a scale model of a tanker, the "Esso Osaka" (Fig. 1), which allows different guidance and control strategies to be tested in a natural environment, but it is not have the same type of hull as surface autonomous vehicles do.

The application of autonomous guidance and control technologies to marine vehicles is an important goal because of their lower cost and being able to navigate in multiple mission or test scenarios. Typically such autonomous vehicles must have good maneuverability and be able to keep an optimal path, normally in shallow waters and confined spaces, under the influence of external disturbances such as currents, wind and waves. Therefore we introduce a guidance and control system capable of controlling the path followed by marine surface vehicles.

In this chapter, we design a model of the "Esso Osaka" tanker to demonstrate the performance of the guidance and control systems. The whole system can be implemented and evaluated through tests in lakes or other confined bodies of water.

Basically, autonomous vehicles must have three subsystems on board the platform: guidance, navigation and control. Here we offer a line-of-sight (LOS) algorithm to solve the above problem. Trajectory points can be generated using many criteria, usually based on the specific vehicle and relevant 
Table 2. Four sub problems of the Mayer problem.

\begin{tabular}{|c|c|c|c|}
\hline Year & Author & Method & Main idea \\
\hline 2000 & Chung, Qi [84] & $\begin{array}{l}\text { Successive learning track-keeping control } \\
\text { (SLTC) algorithm }\end{array}$ & $\begin{array}{l}\text { 1. Correctly maintain track-keep the requirement tar- } \\
\text { get track of set points or minor path. } \\
\text { 2. After the initial off-track disturbance, the first } 3 \text { to } \\
5 \text { tracks of the learning process are taken to move } \\
\text { the vehicle in a zigzag track. }\end{array}$ \\
\hline 2003 & Fossen [90] & Trajectory tracking control based on LOS & $\begin{array}{l}\text { 1. Geometric assignment based on the LOS projection } \\
\text { algorithm for minimization of the cross-track error } \\
\text { to the path. } \\
\text { 2. The desired speed along the path can be specified } \\
\text { independently. }\end{array}$ \\
\hline 2003 & Velagic, Vukic, Omerdic [191] & Adaptive Sugeno fuzzy type autopilot & $\begin{array}{l}\text { Used in an ordinary feedback loop. The adjustable } \\
\text { scaling factor mechanism in an additional feedback } \\
\text { loop. }\end{array}$ \\
\hline 2004 & Breivik, Fossen $[11,12]$ & Guidance-based approach & $\begin{array}{l}\text { 1. A way to specifically control the velocity vector of } \\
\text { the vehicles in such a way that they converge to } \\
\text { follow the desired geometrical paths in a natural } \\
\text { and elegant manner. }\end{array}$ \\
\hline 2007 & Moreire, Fossen, Soares [156] & $\begin{array}{l}\text { Way-point guidance algorithm based on } \\
\text { LOS }\end{array}$ & $\begin{array}{l}\text { 1. Calculation of a dynamic LOS vector norm to im- } \\
\text { prove the convergence of the vehicle to the desired } \\
\text { trajectory. } \\
\text { 2. Independent of the initial design value for the LOS } \\
\text { distance (radius). }\end{array}$ \\
\hline 2009 & Lee, Surendran, Kim [112] & PID control algorithm and fuzzy logic & $\begin{array}{l}\text { Numerical simulations are carried out to discuss } \\
\text { heading control. }\end{array}$ \\
\hline
\end{tabular}

information such as environmental and geographical data (wind, waves, currents, shallow water, islands, etc.), obstacles and collision avoidance (introducing safety margins) and feasibility meaning that every point must be satisfied [87].

There are several methods for determining the optimal path of ship maneuvers summarized in Table 2, Fossen, Breivik and Fossen offer a general method for finding the optimal path, but Moreira, Fossen and Soares use a special approach that is based on a way-point guidance LOS algorithm [94] A new approach can improve the convergence of the LOS algorithm to minimize the crosstrack error by the calculation of a dynamic LOS vector norm. For example, the shortest distance between the vehicle and a straight line [160].

A mathematical model of the "Esso Osaka" tanker is used to simulate the results an demonstrate the performance of the system. This approach is simple to apply to other vehicles or extend to higher dimensional control and guidance problems.

\section{Inland Ship Maneuvers}

First we discuss ocean-going ship-steering autopilots designed to implement course-keeping maneuvers in the open sea and course-changing maneuvers along the coast. Typically, the most important performance criterion for the coursekeeping maneuver is minimum course deviation with smallest control exertion. However, it is desirable to track the new set course as quickly as possible with minimum overshoot [86]. Many controllers arc designed to achieve optimal control performance during course-keeping and course-changing ma- neuvers [106]. Of greatest concern for control of ocean-going vessels is the heading angle.

For inland ships, the autopilot does not so much aim to control the heading angle of the ship as the turning rate. In practice, the captain should track the ship route and consider this when calculating the required turning rate. This is reference input for the inland ship autopilot serves [85]. Hence, the yaw-rate-control is a useful tool for the inland ship captains.

Recent progress in computer science progress has made the use of Global Positioning System (GPS) technology for trackkeeping autopilots become more practical. Theoretically, once the track of the ship is defined the ship can sail automatically without interference from the captain [95]. However, we still believe that an experienced captain is more reliable than an autopilot for inland sailings and then human beings are better at dealing with unexpected incidents. Hence, the captain's input is indispensable to help determine the turning-ratecontrol of the autopilot. This is the preferred operation mode.

Wave filtering is a central issue when designing the autopilot for ocean-going vessels. It is important that the autopilot only compensate for the low-frequency wave force rather than the high-frequency oscillatory force [96]. The central issue for inland vessels is avoidance of collisions. Interference mainly comes from wind gusts and encounters with other ships.

Therefore, inland ships should have optimal maneuvering to avoid collisions. Always pushing the actuator to unknowingly exceed its saturation (SAT) and slew rate limitation (SRI) boundary will lead to considerable deterioration of the 


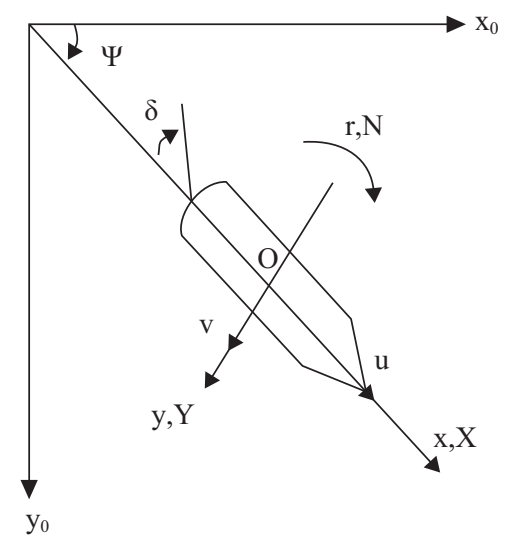

Fig. 2. Definition of motion in the horizontal plane [189].

maneuverability of the ship [6]. An automatic gain reduction technique has been offered to avoid actuator SRL which may lead to the controller wind-up problem [190]. Another technique is the reference conditioning technique to avoid actuator SAT that may also lead to undesirable controller wind-up problems [162].

When designing ships for inland waters both the actuator SAT and SRL should be considered. There is a technique for realizing an inversion in terms of non inverted dynamics in a local feedback loop, the inversion by feedback technique [92]. If this can be accomplished the SAT and SRL boundaries will be avoided.

Based on Newton's law in space-fixed coordinates $\mathrm{x}_{0}-\mathrm{y}_{0}$ are used to define the equations of motion describing the steering dynamics of a ship arc (Fig. 2).

In the section we discuss the internal model control (IMC) approach to designing a turning rate control autopilot. The most important thing to remember is that IMC is a modelbased design approach, so it satisfies the required system response time [155]. After numerical testing we discover that this approach offers captains a very convenient way to tune the autopilot to meet different maneuvering requirements.

The above complex formula of motion in the horizontal plane is simplified, after which the IMC is used to solve the problem and the results tested. Fig. 3(a) shows that a smooth transition is reached and the reference turning rate is also achieved within in $20 \mathrm{~s}$ when the initial speed of response parameter $\beta$ is set to 0.1 and the controller uses a constant reference turning rate of $2.5 \mathrm{o} / \mathrm{s}$. Fig. 3(b) gives the regular pattern for the rudder angle. Specifically, the SRL and SAT have been reached. After a short period of oscillation, the rudder is maintained at a constant value slightly lower than the SAT limit.

The IMC approach implements the SAT and SRL nonlinearities in a local feedback loop and allows the controller to exert its full power without pushing the actuator to exceed its SAT or SRL boundaries [188]. This is an important study because it describes inland ship maneuvering in a limited space with random encounters with other vessels.

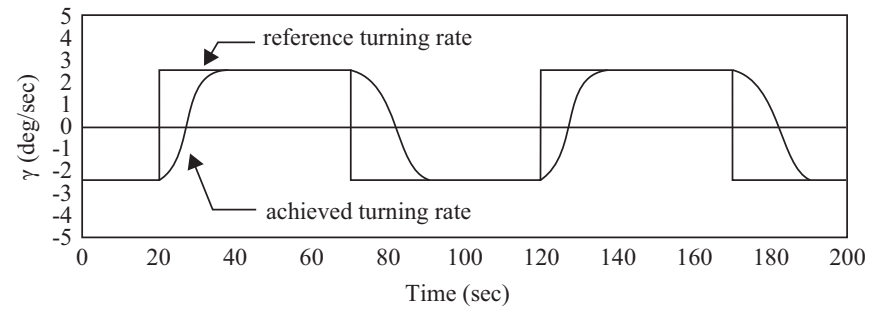

(a)

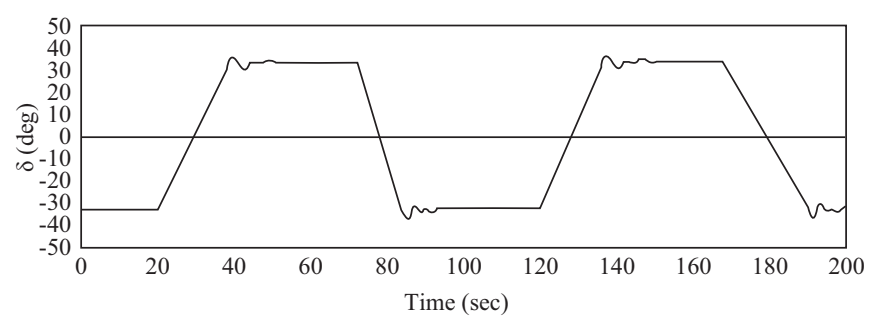

(b)

Fig. 3. (a) Controlled turning rate (b) Rudder angle [189].

\section{APPLICATION SUMMARY}

Our final goal is to find a approach which can arrive determine optimal maneuvering under any sea conditions. Unfortunately, this is a difficult task, because there are many factors that will affect the formulation. Motivated by the work of Bishop and Price [10] and Bailey et al. [7] a unified statespace model for optimal of ship maneuvering, state-keeping, and control in a seaway is derived. There are two main directions should be considered of the dynamic equations of motion for ship maneuvering:

- Maneuvering theory

- Seakeeping theory

An ideal unified theory for determining ship motion could be applied to different sea states, speeds and operations, assuming that the motion of the ship is in calm water, for example in a harbor or in sheltered waters.

In order to conveniently test performance and design of feedback control systems, the time-domain should be defined.

Feedback control system designs for ships have a long history, dating back to 1908 . In recent yearsm the development of global satellite navigation systems and inertial measurements technology have made possible the design of nonlinear model-based ship control systems. This evolution is described in Table 3.

The unified model is derived using a state-space method. This is the standard representation used in feedback control systems. Hence the unified model can be used to simulate ship maneuvers given different sea states and at any speed. Note this model can also satisfy nonlinear maneuvering formulas by unifying the theories of seakeeping and maneuvering [89]. 
Table 3. Evolution of feedback control systems.

\begin{tabular}{|l|l|l|}
\hline Year & \multicolumn{1}{|c|}{ Author } & \multicolumn{1}{c|}{ Contribution } \\
\hline 1908 & Anschutz & Invention of the North-seeking gyroscope \\
\hline 1911 & Sperry [1] & Ballistic gyroscope \\
\hline 1922 & Minorsky [154] & Analysis of the three-term PID-controller \\
\hline 1976 & Balchen [8] & Wave filtering technique \\
\hline 1994,2002 & Fossen [86, 88] & Using Lyapunov methods for stability analysis to design nonlinear ship control systems \\
\hline
\end{tabular}

Table 4. Major ship maneuver pattern theories.

\begin{tabular}{|l|l|l|}
\hline \multicolumn{1}{|c|}{ Central theory } & \multicolumn{1}{|c|}{ Description } & \multicolumn{1}{|c|}{ Usage } \\
\hline $\begin{array}{l}\text { Sequential gradient-restoration } \\
\text { algorithm (SGRA) }\end{array}$ & $\begin{array}{l}\text { Solve special cases of the Mayer problem including } \\
\text { the Bolza problem. }\end{array}$ & $\begin{array}{l}\text { The algorithm can be used fo find the optimal } \\
\text { seaway for a moving ship that needs to change } \\
\text { course or sidestep with time. }\end{array}$ \\
\hline "Esso Osaka" model & $\begin{array}{l}\text { Improve ship guidance and control to find an optimal } \\
\text { seaway path. }\end{array}$ & $\begin{array}{l}\text { Reduce overall distance for ships that want to dy- } \\
\text { namically call at many harbors. }\end{array}$ \\
\hline $\begin{array}{l}\text { Internal model control (IMC) } \\
\text { approach }\end{array}$ & $\begin{array}{l}\text { Design a model for inland ship maneuvering in a } \\
\text { limited space with randomized encounters with } \\
\text { other vessels. }\end{array}$ & $\begin{array}{l}\text { In an environment where one can randomly en- } \\
\text { counter other ships, the captain will conveniently } \\
\text { avoid such encounters given limited space. }\end{array}$ \\
\hline
\end{tabular}

The nonlinear unified state-space model is used to consider the three situations in Table 3. The method can improve performance to avoid collisions during ship maneuvering in natural environment, find the optimal seaway path that will reduce time wastage and satisfy the requirements for inland ship maneuvering in limited space.

Now the nonlinear unified state-space model is used to consider three situations as in the Table 4. It can offer improved collision avoidance performance during maneuvering in particular natural environments, optimize the path on the seaway to reduce time wastage and satisfy the requirements for inland ship maneuvering in a limited space.

\section{CONCLUSIONS}

In this study the literature related to optimal turning and ship maneuvering has been reviewed. Simple classifications of different approaches depending upon different practical purposes and areas have been defined. However an overall model to control of ship maneuvering in a natural environment for any type of ship has not been designed, because there are so many factors that will affect the formulation. Hence our strategy is to use the nonlinear unified state-space model, joined with another approach according to the requirements of the situation. In this way, no matter what the conditions are, an optimal method to solve any problem can always be found, while still noting the restrictions of one of the whole approaches.

Future work will focus on particular problems related to this study. Perhaps some features in each approach can be combined with others. It is hard to determine which one is more significant and valuable than the other. Therefore, we hope to attract more scholars to join this work, and do a more comprehensive study. At the same time, the different types of ship should be considered gradually. Our final goal is to develop a suitable system to determine optimal ship maneuvering for any type of ship in our particular natural environment.

\section{ACKNOWLEDGMENTS}

The authors are appreciative of the financial support in the form of research grants to Dr. Chen-Yuan Chen from the National Science Council, Republic of China under Grant Nos. NSC 99-2628-E153-001 and NSC 100-2628-E153-001. The authors also wish to voice his appreciation for the kind assistance of Professor Chein-Shan Liu, Editor of the Journal of Marine Science and Technology, and would also like to thank the anonymous reviewers for their constructive suggestions which have greatly aided in the improvement of this paper.

\section{REFERENCES}

1. Allensworth, T., "A short history of sperry marine," from http://www. sperry-marine.com/pages/history.html (1999).

2. Almutairi, N. B. and Zribi, M., "Sliding mode control of a threedimensional overhead crane," Journal of Vibration and Control, Vol. 15, No. 11, pp. 1679-1730 (2009).

3. Amerongen, J. V. and Lemke, H. R. V. N., "Criteria for optimum steering of ships," Department of Electrical Engineering, Delft University of Technology, Delft, Netherlands (1980). (Report)

4. Amini, F. and Vahdani, R., "Fuzzy optimal control of uncertain dynamic characteristics in tall buildings subjected to seismic excitation," Journal of Vibration and Control, Vol. 14, No. 12, pp. 1843-1867 (2009).

5. Asinovsky, V., "Features of maneuverability of ships with steering nozzles," Marine Technology, Vol. 23, No. 1, pp. 23-34 (1986).

6. Astrom K. J. and Wittenmark B., Adaptive Control. Reading, AddisonWesley, MA (1995).

7. Bailey, P. A., Price, W. G., and Temarel, P., "A unified mathematical model describing the maneuvering of a ship travelling in a seaway," RINA, Vol. 
140, pp. 131-149 (1998). (Trans)

8. Balchen, J. G., Jenssen, N. A., and Salid, S., "Dynamic positioning using Kalman filtering and optimal control theory," Proceedings of the IFAC/ IFIP Symp. on Automation in Offshore Oil Field Operation, Bergen, Norway, pp. 183-186 (1976).

9. Barr, R. A., "A review and comparison of ship maneuvering simulation methods," Society of Naval Architecture and Marine Engineering, Vol. 101, pp. 609-635 (1993).

10. Bishop, R. E. D. and Price, W. G., "On the use of equilibrium axes and body axis in the dynamics of a rigid ship," Journal of Mechanical Engineering Science, Vol. 23, No. 5, pp. 243-256 (1981).

11. Breivik, M. and Fossen, T. I., "Path following of straight lines and circles for marine surface vessels," Proceedings of the Sixth IFAC CAMS, Ancona, Italy, pp. 65-70 (2004).

12. Breivik, M. and Fossen, T. I., "Path following for marine surface vessels," Proceedings of the OTO'04, Kobe, Japan, pp. 2282-2289 (2004).

13. Chen, C. W., "A critical review of parallel distributed computing and the Lyapunov criterion for multiple time-delay fuzzy systems," International Journal of the Physical Sciences, Vol. 6, No. 19, pp. 4492-4501 (2011).

14. Chen, C. W., "Application of fuzzy-model-based control to nonlinear structural systems with time delay: an LMI method," Journal of Vibration and Control, Vol. 16, pp. 1651-1672 (2010).

15. Chen, C. W., "Applications of LDI-based criterion to a nonlinear chaotic system: a critical review," Journal of Vibration and Control (accepted).

16. Chen, C. W., "Applications of the fuzzy lyapunov lmi criterion to a chaotic structural system," Journal of Vibration and Control (accepted).

17. Chen, C. W., "Delay independent criterion for multiple time-delay systems and its application in building structure control systems," Journal of Vibration and Control (accepted).

18. Chen, C. W., "Fuzzy control of interconnected structural systems using the fuzzy lyapunov method," Journal of Vibration and Control, Vol. 17 No. 11, pp. 1693-1702 (2011)

19. Chen, C. W., "Internet services and interface design for marketing: preliminary study of cliven products," International Journal of the Physical Sciences, Vol. 6, No. 15, pp. 3585-3596 (2011)

20. Chen, C. W., "Modeling and control for nonlinear structural systems via a nn-based approach," Expert Systems with Applications, Vol. 36, pp. 4765-4772 (2009).

21. Chen, C. W., "Modeling and fuzzy pdc control and its application to an oscillatory tlp structure," Mathematical Problems in Engineering- An Open Access Journal, DOI: 10.1155/2010/120403 (2010).

22. Chen, C. W., "Modeling, control and stability analysis for time-delay tlp systems using the fuzzy lyapunov method," Neural Computing and Applications, Vol. 20, No. 4, pp. 527-534 (2011).

23. Chen, C. W., "Stability analysis and robustness design of nonlinear systems: an nn-based approach," Applied Soft Computing, Vol. 11, No. 2, pp. 2735 2742 (2011).

24. Chen, C. W., "Stability conditions of fuzzy systems and its application to structural and mechanical systems," Advances in Engineering, Software, Vol. 37, pp. 624-629 (2006)

25. Chen, C. W., "The stability of an oceanic structure with T-S fuzzy models," Mathematics and Computers in Simulation, Vol. 80, pp. $402-426$ (2009).

26. Chen, C. W., Chang, M. L., and Tseng, C. P., "Critical human factor evaluation of knowledge sharing intention in taiwanese enterprises," Human Factors and Ergonomics in Manufacturing \& Service Industries, DOI: 10.1002/hfm.20300 (2012).

27. Chen, C. W., Chang, M. L., and Tseng, C. P., "The human factors of knowledge sharing intention among Taiwanese enterprises: a model of hypotheses," Human Factors and Ergonomics in Manufacturing \& Service Industries, DOI: 10.1002/hfm.20286 (2012).

28. Chen, C. W. and Chen, P. C., "Ga-based adaptive neural network controllers for nonlinear systems," International Journal of Innovative Computing, Information and Control, Vol. 6, pp. 1793-1803 (2010).

29. Chen, C. W., Chen, P. C., and Chiang, W. L., "Stabilization of adaptive neural network controllers for nonlinear structural systems using a singular perturbation approach," Journal of Vibration and Control, Vol. 17,
No. 8, pp. 1241-1252 (2011).

30. Chen, C. W., Chen, T. H., and Lin, Y. F., "The statistical analysis for consumers' intensions of purchasing cosmetics," African Journal of Business Management, Vol. 5, No. 20, pp. 8271-8276 (2011).

31. Chen, C. W., Chiang, W. L., and Hsiao, F. H., "Stability analysis of t-s fuzzy models for nonlinear multiple time-delay interconnected systems," Mathematics and Computers in Simulation, Vol. 66. pp. 523-537 (2005).

32. Chen, C. W., Chiang, W. L., and Tsai, C. H., "Fuzzy lyapunov method for stability conditions of nonlinear systems," International Journal on Artificial Intelligence Tools, Vol. 15, pp. 163-171 (2006).

33. Chen, C. W., Lee, K. L., and Tseng, C. P., "The relationship between personality traits and sales force automation usage: a preliminary study," Human Factors and Ergonomics in Manufacturing \& Service Industries (accepted)

34. Chen, C. W., Lin, C. L., and Tsai, C. H., "A novel delay-dependent criteria for time-delay t-s fuzzy systems using fuzzy lyapunov method," International Journal on Artificial Intelligence Tools, Vol. 16, pp. 545-552 (2007).

35. Chen, C. W., Shen, C. W., and Jeng, M. J., "Stability analysis of an oceanic structure using the lyapunov method," Engineering Computations, Vol. 27 , pp. 186-204 (2010).

36. Chen, C. W., Tseng, C. P., Lee, K. L., and Yang, H. C., "Conceptual framework and research method for personality traits and sales force automation usage," Scientific Research and Essays, Vol. 6, No. 17, pp. 3784 3793 (2011).

37. Chen, C. W., Wang, M. H. L., and Lin, J. W., "Managing target the cash balance in construction firms using a fuzzy regression approach," International Journal of Uncertainty, Fuzziness and Knowledge-Based Systems, Vol. 17, pp. 667-684 (2009).

38. Chen, C. W., Wang, H. L., Liu, F. R., and Chen, T. H., "Application of project cash management and control for infrastructure," Journal of Marine Science and Technology, Vol. 18, pp. 644-651 (2010).

39. Chen, C. W., Yang, P. H. C., Chang, A. K. H., and Chen, T. H., "Evaluation of inference adequacy in cumulative logistic regression models: an empirical validation of isw-ridge relationships," China Ocean Engineering, Vol. 22, pp. 43-56 (2008).

40. Chen, C. W., Yang, P. H. C., and Chen, T. H., "Analysis of experimental data on internal waves with statistical method," Engineering Computations-International Journal for Computer-Aided Engineering and Software, Vol. 24, pp. 116-150 (2007).

41. Chen, C. W., Yeh, K., Chiang, W. L., and Wu, D. J., "Modeling, $\mathrm{H}^{\infty}$ control and stability analysis for structural systems using takagi-sugeno fuzzy model," Journal of Vibration and Control, Vol. 13, pp. 1519-1534 (2007).

42. Chen, C. W., Yeh, K., and Liu, K. F. R., "Adaptive fuzzy sliding mode control for seismically excited bridges with lead rubber bearing isolation," International Journal of Uncertainty, Fuzziness and KnowledgeBased Systems, Vol. 17, pp. 705-727 (2009).

43. Chen, C. W., Yeh, K., Liu, K. F. R., and Lin, M. L., "Applications of fuzzy control to nonlinear time-delay systems using the linear matrix inequality fuzzy Lyapunov method," Journal of Vibration and Control, DOI: 10.1177/1077546311410765 (2012).

44. Chen, C. Y., "A critical review of internal wave dynamics. Part 1 -Remote sensing and in-situ observations," Journal of Vibration and Control, DOI: 10.1177/1077546310395971 (2011).

45. Chen, C. Y., "A critical review of internal wave dynamics. Part 2 Laboratory experiments and theoretical physics," Journal of Vibration and Control, DOI: 10.1177/1077546310397561 (2011).

46. Chen, C. Y., "A critical review and improvement method on biped robot," International Journal of Innovative Computing, Information and Control, Vol. 7, No. 9, pp. 5245-5254 (2011).

47. Chen, C. Y., "Statistical and dynamical analyses of propagation mechanisms of solitary internal waves in a two-layer stratification," Journal of Marine Science and Technology, Vol. 16, No. 1, pp. 100-114, DOI: 10.1007/s00773-010-0112-z (2011).

48. Chen, C. Y., "Using discriminant analysis to determine the breaking criterion for an ISW propagating over a ridge," Environmental Fluid 
Mechanics, Vol. 10, pp. 577-586 (2010).

49. Chen, C. Y., Chen, C. W., and Tseng, I. F., "Localized mixing due to an interfacial solitary wave breaking on seabed topography in different ridge heights," Journal of Offshore Mechanics and Arctic Engineering, Vol. 129, pp. 245-250 (2007).

50. Chen, C. Y., Hsu, J. R. C., and Chen, C. W., "Fuzzy logic derivation of neural network models with time delays in subsystems," International Journal on Artificial Intelligence Tools, Vol. 14, pp. 967-974 (2005).

51. Chen, C. Y., Hsu, J. R. C., and Chen, C. W., "Generation of internal solitary wave by gravity collapse," Journal of Marine Science and Technology, Vol. 15, pp. 1-7 (2007)

52. Chen, C. Y., Hsu, J. R. C., and Chen, C. W., "Wave propagation at the interface of a two-layer fluid system in the laboratory," Journal of Marine Science and Technology, Vol. 15, pp. 8-16 (2007).

53. Chen, C. Y., Hsu, J. R. C., Chen, C. W., and Cheng, M. H., "Numerical model of an internal solitary wave evolution on impermeable variable seabed in a stratified two-layer fluid system," China Ocean Engineering, Vol. 20, pp. 303-313 (2006).

54. Chen, C. Y., Hsu, J. R. C., Cheng, M. H., and Chen, C. W., "Experiments on mixing and dissipation in internal solitary waves over two triangular obstacles," Environmental Fluid Mechanics, Vol. 8, pp. 199-214 (2008).

55. Chen, C. Y. and Huang, P. H., "Review of an autonomous humanoid robot and its mechanical control," Journal of Vibration and Control, DOI: 10.1177/1077546310395974 (2011).

56. Chen, C. Y., Lee, W. I., Kuo, H. M., Chen, C. W., and Chen, K. H., "The study of a forecasting sales model for fresh food," Expert Systems with Applications, Vol. 37, pp. 7696-7702 (2010).

57. Chen, C. Y., Lin, C. L., Tseng, I. F., and Chen, C. W., "Dynamic behavior of an internal solitary wave oscillating over variable bathymetry," Kuwait Journal of Science \& Engineering, Vol. 34, pp. 153-166 (2007).

58. Chen, C. Y., Lin, J. W., Lee, W. I., and Chen, C. W., "Fuzzy control for an oceanic structure: A case study in time-delay tlp system," Journal of Vibration and Control, Vol. 16, pp. 147-160 (2010).

59. Chen, C. Y., Liu, K. C., Liu, Y. W., and Huang, W. C., "A case study of reinforced concrete short column under earthquake using experimental and theoretical investigations," Structural Engineering and Mechanics, Vol. 36, pp. 197-206 (2010).

60. Chen, C. Y., Shen, C. W., Chen, C. W., Liu, K. F. R., and Jeng, M. J., “A stability criterion for time-delay tension leg platform systems subjected to external force," China Ocean Engineering, Vol. 23, pp. 49-57 (2009).

61. Chen, C. Y., Shih, B. Y., Chen, Z. S., and Chen, T. H., "The exploration of internet marketing strategy by search engine optimization: a critical review and comparison," African Journal of Business Management, Vol. 5, No. 12, pp. 4644-4649 (2011)

62. Chen, C. Y., Shih, B. Y., and Chou, W. C., "Obstacle avoidance design for a humanoid intelligent robot with ultrasonic sensors," Journal of Vibration and Control, Vol. 17, No. 12, pp. 1798-1804, DOI: 10.1177/1077546310381101 (2011).

63. Chen, C. Y., Shih, B. Y., and Chou, W. C., "The development of autonomous low cost biped mobile surveillance robot by intelligent bricks," Journal of Vibration and Control, DOI: 10.1177/1077546310371349 (2011).

64. Chen, C. Y., Shyue, S. W., and Chang, C. J., "Association rule mining for evaluation of regional environments: case study of dapeng bay, taiwan," International Journal of Innovative Computing, Information and Control, Vol. 6, pp. 3425-3436 (2010).

65. Chen, C. Y., Tseng, I. F., Yang, H. C. P., Chen, C. W., and Chen, T. H., "Profile evolution and energy dissipation for internal soliton transmitting over different submarine ridges," China Ocean Engineering, Vol. 20, pp. 585-594 (2006).

66. Chen, C. Y., Yang, H. C., Chen, C. W., and Chen, T. H., "Diagnosing and revising logistic regression models: effect on internal solitary wave propagation," Engineering Computations-International Journal for Computer-Aided Engineering and Software, Vol. 25, pp. 121-139 (2008).

67. Chen, C. Y., Yang, Y. F., Chen, C. W., Chen, L. T., and Chen, T. H., "Linking the balanced scorecard (bsc) to business management performance: a preliminary concept of fit theory for navigation science and management," International Journal of the Physical Sciences, Vol. 5, pp. 12961305 (2010).

68. Chen, H. H., "Some aspects of ship maneuverability," Journal of Ship Research, Vol. 13, No. 2, pp. 111-128 (1969).

69. Chen, L. T. and Chen, C. W., "Are educational background and gender moderator variables for leadership, satisfaction and organizational commitment," African Journal of Business Management, Vol. 4, pp. 248-261 (2010).

70. Chen, P. C., Chen, C. W., and Chiang, W. L., "Ga-based fuzzy sliding mode controller for nonlinear systems," Mathematical Problems in Engineering- An Open Access Journal DOI: 10.1155/2008/325859 (2008d).

71. Chen, P. C., Chen, C. W., and Chiang, W. L., "Ga-based modified adaptive fuzzy sliding mode controller for nonlinear systems," Expert Systems with Applications, Vol. 36, pp. 5872-5879 (2009).

72. Chen, P. C., Chen, C. W., and Chiang, W. L., "Linear matrix inequality conditions of nonlinear systems by genetic algorithm-based adaptive fuzzy sliding mode controller," Journal of Vibration and Control, Vol. 17, No. 2, pp. 163-173 (2011).

73. Chen, P. C., Chen, C. W., Chiang, W. L., and Lo, D. C., "Ga-based decoupled adaptive fsimc for nonlinear systems by a singular perturbation scheme," Neural Computing and Applications, Vol. 20, No. 4, pp. 517 526 (2011).

74. Chen, P. C., Chen, C. W., Chiang, W. L., and Yeh, K., "A novel stability condition and its application to ga-based fuzzy control for nonlinear systems with uncertainty," Journal of Marine Science and Technology, Vol. 17, pp. 293-299 (2009).

75. Chen, T. H. and Chen, C. W., "Application of data mining to the spatial heterogeneity of foreclosed mortgages," Expert Systems with Applications, Vol. 37, pp. 993-997 (2010).

76. Chen, T. H., Chen, C. Y., Yang, C. H. P., and Chen, C. W., "A mathematical tool for inference in logistic regression with small-sized data sets - a practical application on isw-ridge relationships," Mathematical Problems in Engineering- An Open Access Journal, DOI: $10.1155 / 2008 / 186372(2008)$.

77. Chen, T. H., Yang, H. C. P., Chen, C. Y., and Chen, C. W., "Application of logistic regression model: propagation effect on internal soliton," Journal of Chung Cheng Institute of Technology, Vol. 37, pp. 1-10 (2009).

78. Chen, W. T. and Saif, M., "Fuzzy nonlinear unknown input observer design with fault diagnosis applications," Journal of Vibration and Control, Vol. 16, No. 3, pp. 377-401 (2010).

79. Cheng, M. H. and Hsu, J. R. C., "Laboratory experiments on waveform inversion of an internal solitary wave over a slope-shelf," Environmental Fluid Mechanics, Vol. 11, No. 4, pp. 353-384 (2011).

80. Chiang, T. C. and Wang, W. J., "Highway on-ramp control using fuzzy decision making," Journal of Vibration and Control, Vol. 17, No. 2, pp. 205-213 (2011)

81. Chiang, W. L., Chiou, D. J., Tang, J. P., Hsu, W. K., and Liu, T. Y., "Detecting the sensitivity of structural damage based on the hilbert-huang transform approach," Engineering Computations, Vol. 27, pp. 799-818 (2010).

82. Chiou, D. J., Hsu, W. K., Chen, C. W., Hsieh, C. M., Tang, J. P., and Chiang, W. L., "Applications of hilbert-huang transform to structural damage detection," Structural Engineering and Mechanics, Vol. 39, No. 1, pp. 1-20 (2011).

83. Chu, T. H., Lin, M. L., Chang, C. H., and Chen, C. W., "Developing a tour guiding information system for tourism service using mobile gis and gps techniques," Advances in Information Sciences and Service Sciences, Vol. 3, No. 6, pp. 49-58 (2011).

84. Chung, J. S. and Qi, T., "Smart seafloor mining vehicle: simulation with successive learning track-keeping control," International Journal of Offshore and Polar Engineering, Vol. 10, No. 3, pp. 182-186 (2000).

85. Duetz, H., "An adaptive autopilot for inland ships," Proceedings of the IFAC Conference on Adaptive Systems in Control and Signal Processing, Glasgow, U.K., pp. 283-288 (1989).

86. Fossen, T. I., Guidance and Control of Ocean Vehicles, John Wiley and 
Sons, Chichester, England (1994).

87. Fossen, T. I., Marine Control Systems: Guidance, Navigation and Control of Ships, Rigs and Underwater Vehicles, Marine Cybernetics AS, Trondheim, Norway (2000).

88. Fossen, T. I., Marine Control Systems: Guidance, Navigation and Control of Ships, Rigs and Underwater Vehicles, Marine Cybernetics AS, Trondheim, Norway (2002).

89. Fossen, T. I., "A nonlinear unified state-space model for ship maneuvering and control in a seaway," International Journal of Bifurcation and Chaos, Vol. 15, No. 9, pp. 2717-2746 (2005).

90. Fossen, T. I., Breivik, M., and Skjetne, R., "Line-of-sight path following of underactuated marine craft," Proceedings of the Sixth IFAC conference on Maneuvering and Control of Marine Crafts, Girona, Spain, pp. 244-249 (2003).

91. Gonzalez, S. and Miele, A., "Sequential gradient-restoration algorithm for optimal control problems with general boundary conditions," Journal of Optimization Theory and Applications, Vol. 26, No. 3, pp. 395-425 (1978).

92. Goodwin, G. C., Graebe, S. E., and Salgado, M. E., "Principles of control system design," Department of Electrical and Computer Engineering, University of Newcastle, Callaghan, Australia (1997).

93. Guclu, R. and Metin, M., "Fuzzy logic control of vibrations of a light rail transport vehicle in use in istanbul traffic," Journal of Vibration and Control, Vol. 15, No. 9, pp. 1423-1440 (2009).

94. Healey, A. J. and Lienard, D., "Multivariable sliding mode control for autonomous diving and steering of unmanned underwater vehicles," IEEE Journal of Oceanic Engineering, Vol. 18, No. 3, pp. 327-339 (1993).

95. Holzhuter, T., "A high precision track controller for ships," Proceedings of the 11th IFAC World Congress, Tallinn, Estonia, pp. 118-123 (1990). (preprints)

96. Holzhuter, T. and Strauch, H., "A commercial adaptive autopilot for ships: Design and experimental experience," Proceedings of the 10th IFAC World Congress, Munich, Germany, pp. 226-230 (1987).

97. Hsiao, F. H., Chen, C. W., Liang, Y. W., Xu, S. D., and Chiang, W. L., "T-s fuzzy controllers for nonlinear interconnected systems with multiple time delays," IEEE Trans. Circuits \& Systems-I: Regular Papers, Vol. 52, pp. 1883-1893 (2005).

98. Hsiao, F. H., Chen, C. W., Wu, Y. H., and Chiang, W. L., "Fuzzy controllers for nonlinear interconnected tmd systems with external force," Journal of The Chinese Institute of Engineers, Vol. 28, pp. 175-181 (2005).

99. Hsiao, F. H., Chiang, W. L., and Chen, C. W., "Fuzzy control for nonlinear systems via neural-network-based approach," International Journal for Computational Methods in Engineering Science and Mechanics, Vol. 6, pp. 145- 152 (2005).

100. Hsiao, F. H., Chiang, W. L., Chen, C. W., Xu, S. D., and Wu, S. L., "Application and robustness design of fuzzy controller for resonant and chaotic systems with external disturbance," International Journal of Uncertainty, Fuzziness and Knowledge-Based System, Vol. 13, pp. 281295 (2005).

101. Hsiao, F. H., Hwang, J. D., Chen, C. W., and Tsai, Z. R., "Robust stabilization of nonlinear multiple time-delay large-scale systems via decentralized fuzzy control," IEEE Trans. Fuzzy Systems, Vol. 13, pp. 152-163 (2005).

102. Hsieh, T. Y., Wang, M. H. L., and Chen, C. W., "A new viewpoint of s-curve regression model and its application to construction management," International Journal on Artificial Intelligence Tools, Vol. 15, pp. 131-142 (2006).

103. Hsu, W. K., Huang, P. C., Chang, C. C., Chen, C. W., Hung, D. M., and Chiang, W. L., "An integrated flood risk assessment model for property insurance industry in Taiwan," Natural Hazards, Vol. 58, No. 3, pp. 1295-1309 (2011)

104. Inoue, S., Hirano, M., Kijima, K., and Takashina, J., "A practical calculation method of ship maneuvering motion," International Shipbuilding Progress, Vol. 28, No. 325, pp. 207-222 (1981)

105. Jayaswal, P., Verma, S. N., and Wadhwani, A. K., "Development of ebp-artificial neural network expert system for rolling element bearing fault diagnosis," Journal of Vibration and Control, Vol. 17, No. 8, pp. 1131-1148 (2011).

106. Kallstorm, C. C. and Theoren, K., "Turning controller for ships," Proceedings of the IFAC Workshop on Control Applications in Marine Systems, Genova. Italy, pp. 245-254 (1992).

107. Kring, D. and Sclavounos, P. D., "Numerical stability analysis for timedomain ship motion simulation," Journal of Ship Research, Vol. 39, No. 4, pp. 313-320 (1995).

108. Kuo, H. M. and Chen, C. W., "Application of quality function deployment to improve the quality of Internet shopping website interface design," International Journal of Innovative Computing, Information and Control, Vol. 7, No. 1, pp. 253-268 (2011).

109. Kuo, H. M. and Chen, C. W., "A novel viewpoint on information and interface design for auction website," Human Factors and Ergonomics in Manufacturing \& Service Industries, DOI: 10.1002/hfm.20274 (2012).

110. Kuo, H. M. and Chen, C. W., "A study of b2c supporting interface design system for the elderly," Human Factors and Ergonomics in Manufacturing \& Service Industries, DOI: 10.1002/hfm.20297 (2012).

111. Kuo, H. M., Chen, C. W., and Chen, C. W., "A study of merchandise information and interface design on $\mathrm{B} 2 \mathrm{C}$ websites," Journal of Marine Science and Technology, Vol. 19, No. 1, pp. 15-25 (2011).

112. Lee, G., Surendran, S., and Kim, S. H., "Algorithms to control the moving ship during harbour entry," Applied Mathematical Modeling, Vol. 33, No. 5, pp. 2474-2490 (2009).

113. Lee, S. C., Lin, P. H., Wang, J. S., Huang, C. H., and Huang, P. H., "Mass media in taiwan and the formation of chien-ming wang's baseball superstar image," International Journal of the Physical Sciences, Vol. 6, pp. 3000-3006 (2011).

114. Lee, S. C., Wang, C. C., Huang, C. C., Wang, J. S., Huang, C. H., and Huang, P. H., "The idolization of chien-ming wang and social psychological factors in taiwan," International Journal of the Physical Sciences, Vol. 6, pp. 2607-2612 (2011).

115. Lee, W. I., "The development of a qualitative dynamic attribute value model for healthcare institutes," Iranian Journal of Public Health, Vol. 39, No. 4, pp. 15-25 (2010).

116. Lee, W. I. and Chen, C. W., "A forecasting model for fresh food sales in pos database: a comparison between the logistic regression, moving average and BPNN methods," Journal of Marine Science and Technology (accepted)

117. Lee, W. I., Chen, C. W., and Chen, T. H., "The relationship between consumer orientation, service value, medical care service quality and patient satisfaction: The case of a medical center in Southern Taiwan," African Journal of Business Management, Vol. 4, pp. 448-458 (2010).

118. Lee, W. I., Chen, C. W., and Wu, C. H., "Relationship between quality of medical treatment and customer satisfaction - a case study in dental clinic association," International Journal of Innovative Computing, Information and Control, Vol. 6, pp. 1805-1822 (2010).

119. Lee, W. I., Chiu, Y. T., and Liu, C. C., "Assessing the effects of consumer involvement and service quality in a self-service setting," Human Factors and Ergonomics in Manufacturing \& Service Industries, Vol. 21, No. 5, pp. 504-515, DOI: 10.1002/hfm.20253 (2011).

120. Li, L., Song, G., and Ou, J., "Nonlinear structural vibration suppression using dynamic neural network observer and adaptive fuzzy sliding mode control," Journal of Vibration and Control, Vol. 16, No. 10, pp. 1503$1526(2010)$

121. Lin, C. L., Wang, J. F., Chen, C. W., and Yen, C. W., "Improving the generalization performance of rbf neural networks using a linear regression technique," Expert Systems with Applications, Vol. 36, pp. 1204912053 (2009).

122. Lin, J. and Chao, W. S., "Vibration suppression control of beam-cart system with piezoelectric transducers by decomposed parallel adaptive neuro-fuzzy control," Journal of Vibration and Control, Vol. 15, No. 12, pp. 1885-1906 (2009).

123. Lin, J. W., Chen, C. W., and Chung, S. H., "Modeling and assessment of bridge structure for seismic hazard prevention," Natural Hazards, DOI: 
10.1007/s11069-011-9969-3 (2011).

124. Lin, J. W., Chen, C. W., and Hsu, T. C., "Fuzzy statistical refinement for the forecasting of tenders for roadway construction," Journal of Marine Science and Technology (accepted).

125. Lin, J. W., Chen, C. W., and Peng, C. Y., "Kalman filter decision systems for debris flow hazard assessment," Natural Hazards, DOI: 10.1007/s11069-011-9907-4 (2012).

126. Lin, J. W., Huang, C. W., and Shih, C. H., "Fuzzy lyapunov stability analysis and nn modeling for tension leg platform systems," Journal of Vibration and Control, Vol. 17, No. 2, pp. 151-158 (2011).

127. Lin, M. L. and Chen, C. W., "Application of fuzzy models for the monitoring of ecologically sensitive ecosystems in a dynamic semi-arid landscape from satellite imagery," Engineering Computations, Vol. 27, pp. 5-19 (2010).

128. Lin, M. L. and Chen, C. W., "Stability analysis of community and ecosystem hierarchies using the lyapunov method," Journal of Vibration and Control, DOI: 10.1177/1077546310385737 (2012).

129. Lin, M. L. and Chen, C. W., "Using gis-based spatial geocomputation from remotely sensed data for drought risk-sensitive assessment," International Journal of Innovative Computing, Information and Control, Vol. 7, No. 2, pp. 657-668 (2011).

130. Lin, M. L., Chen, C. W., Wang, Q. B., and Cao, Y., "Fuzzy model-based assessment and monitoring of desertification using modis satellite imagery," Engineering Computations, Vol. 26, pp. 745-760 (2009).

131. Liu, K. F. R., Hsu, C. Y., Yeh, K., and Chen, C. W., "Hierarchical analytic network process and its application in environmental impact evaluation," Civil Engineering and Environmental Systems, Vol. 28, No. 1, pp. 1-18 (2011).

132. Liu, K. F. R., Lu, C. F., Chen, C. W., and Shen, Y. S., "Applying bayesian belief networks to health risk assessment," Stochastic Environmental Research \& Risk Assessment, DOI: 10.1007/s00477-011-0470-z (2012).

133. Liu, T. Y., Chiang, W. L., Chen, C. W., Hsu, W. K., Lu, L. C., and Chu, T. J., "Identification and monitoring of bridge health from ambient vibration data," Journal of Vibration and Control, Vol. 17, No. 4, pp. 589603 (2011).

134. Liu, T. Y., Chiang, W. L., Chen, C. W., Hsu, W. K., Lin, C. W., Huang, P. C., and Chu, T. J., "Structural system identification for vibration bridges using the Hilbert-Huang transform," Journal of Vibration and Control, doi: 10.1177/1077546311428347 (2012).

135. Mandel, P., "Ship maneuvering and control, principles of naval architecture," in: Comstock, J. P. (Ed.), Society of Naval Architecture and Marine Engineering, New York, New York, pp. 463-606 (1967).

136. Marichal, G. N., Artes, M., and Garcia, P. J. C., "An intelligent system for faulty-bearing detection based on vibration spectra," Journal of Vibration and Control, Vol. 17, No. 6, pp. 931-942 (2011).

137. Metin, M. and Guclu, R., "Active vibration control with comparative algorithms of half rail vehicle model under various track irregularities," Journal of Vibration and Control, Vol. 17, No. 10, pp. 1525-1539 (2011).

138. Miele, A., "Recent advances in gradient algorithms for optimal control problems," Journal of Optimization Theory and Applications, Vol. 17, No. 5-6, pp. 361-430 (1975).

139. Miele, A., "Optimal trajectories of aircraft and spacecraft, aircraft trajectories: computation, prediction, and control," in: Benoit, A. (Ed.), Agardograph No. AG-301, AGARD/NATO, Paris, France, Vol. 1, No 2, pp. 1-56 (1990).

140. Miele, A. and Chao, C. S., "Optimal ship maneuvers: algorithm," AeroAstronautics, Report 288, Rice University (1998).

141. Miele, A., Lee, W. Y., and Wu, G. D., "Ascent performance feasibility of the national aerospace plane," Atti della Accademia delle Scienze di Torino, Vol. 131, pp. 91-108 (1997).

142. Miele, A. and Mancuso, S., "Optimal ascent trajectories and feasibility of next-generation orbital spacecraft," Journal of Optimization Theory and Applications, Vol. 97, No. 3, pp. 519-550 (1998).

143. Miele, A., Pritchard, R. E. and Damoulakis, J. N., "Sequential gradientrestoration algorithm for optimal control problems," Journal of Optimization Theory and Applications, Vol. 5, No. 4, pp. 235-282 (1970).
144. Miele, A. and Wang, T., "Optimal transfers from an earth orbit to a mars orbit," 48th IAF Congress, Turin, Italy, Paper No. IAF-97-A.6.05 (1997).

145. Miele, A. and Wang, T., "Primal-dual properties of sequential gradient-restoration algorithms for optimal control problems, part 1: basic problem, integral methods in science and engineering," in: Payne, F. R. (Ed.), Hemisphere Publishing Corporation, Washington, DC, pp. 577607 (1986).

146. Miele, A. and Wang, T., "Primal-dual properties of sequential gradientrestoration algorithms for optimal control problems, part 2: general problem," Journal of Mathematical Analysis and Applications, Vol. 119, No. 1-2, pp. 21 - 54 (1986).

147. Miele, A., Wang, T., and Chao, C. S., "Equations of motion of a ship: introduction," Aero-Astronautics, Report 285, Rice University (1998).

148. Miele, A., Wang, T., and Chao, C. S., "Equations of motion of a ship: extensions," Aero-Astronautics, Report 286, Rice University (1998).

149. Miele, A., Wang, T., Chao, C. S., and Dabney, J. B., "Optimal course change and sidestep maneuvers for a ship," Aero-Astronautics, Report 290, Rice University (1998).

150. Miele, A., Wang, T., Chao, C. S., and Dabney, J. B., "Optimal control of ship for course change and sidestep maneuvers," Journal of Optimization Theory and Applications, Vol. 103, No. 2, pp. 259-282 (1999).

151. Miele, A., Wang, T., Lee, W. Y., and Zhao, Z. G., "Optimal trajectories for the aeroassisted flight experiment," Acta Astronautica, Vol. 21, No. 11-12, pp. 735-747 (1990).

152. Miele, A., Wang, T., and Melvin, W. W., "Optimal take-off trajectories in the presence of windshear," Journal of Optimization Theory and Applications, Vol. 49, No. 1, pp. 1-45 (1986).

153. Miloh, T. and Pachter, M., "Ship collision avoidance and pursuit-evasion differential games with speed loss," Computers and Mathematics with Applications, Vol. 18, No. 1-3, pp. 77-100 (1989).

154. Minorsky, N., "Directional stability of automatic steered bodies," J. Amer. Soc., Journal of the American Society of Naval Engineers, Vol. 34, No. 2, pp. 280-309 (1992).

155. Morari, M. and Zafirion, U., Robust Process Control, Prentice-Hall, Englewood Cliffs, NI (1989).

156. Moreira, L., Fossen, T. I., and Soares, C. G., "Path following control system for a tanker ship model," Ocean Engineering, Vol. 34, No. 14-15, pp. 2074-2085 (2007).

157. Nambisan, P. R. and Singh, S. N., "Multi-variable adaptive backstepping control of submersibles using sdu decomposition," Ocean Engineering, Vol. 36, No. 2, pp. 158-167 (2009).

158. Narasimhan, M. and Singh, S. N., "Adaptive input-output feedback linearizing yaw plane control of bauv using dorsal fins," Ocean Engineering, Vol. 31, No. 11-12, pp. 1413-1430 (2006).

159. Omurlu, V. E., Engin, S. N., and Yuksek, I., "Application of fuzzy pid control to cluster control of viaduct road vibrations," Journal of Vibration and Control, Vol. 14, No. 8, pp. 1201-1215 (2009).

160. Pettersen, K.Y. and Lefeber, E., "Way-point tracking control of ships," Proceedings of the 40th IEEE Conference on Decision and Control, Orlando, Florida USA, pp. 940-945 (2001).

161. Rishikof, B. H., Mccormick, B. R., Pritchard, R. E., and Sponaugle, S. J., "Segram: a practical and versatile tool for spacecraft trajectory optimization," Acta Astronautica, Vol. 26, No. 8-10, pp. 599-609 (1992).

162. Seron, M. M., Goodwin, G. C., and Graebe, S. F., "Control system design issues for unstable linear systems with saturated inputs," IEE Proceedings-Control Theory and Applications, Vol. 142, No. 4, pp. 335-144 (1995).

163. Shen, C. W., Cheng, M. J., Chen, C. W., Tsai, F. M., and Cheng, Y. C., "A fuzzy ahp-based fault diagnosis for semiconductor lithography process," International Journal of Innovative Computing, Information and Control, Vol. 7, No. 2, pp. 805-816 (2011).

164. Shih, B. Y., Chang, C. J., and Chen, A. W., "Enhanced mac channel selection to improve performance of ieee 802.15.4," International Journal of Innovative Computing, Information and Control, Vol. 6, pp. 55115526 (2010).

165. Shih, B. Y., Chang, H., and Ma, J. M., "Dynamics and control for robot 
manipulators using a greedy algorithm approach," Journal of Vibration and Control, DOI: 10.1177/1077546311407649 (2011).

166. Shih, B. Y. and Chou, W. C., "Obstacle avoidance using a path correction method for autonomous control of a biped intelligent robot," Journal of Vibration and Control, Vol. 17, No. 10, pp. 1567-1573, DOI: 10.1177/1077546310372004 (2011).

167. Shih, B. Y. and Lee, W. I., "A hybrid artificial intelligence salesforecasting system in the convenience store industry," Human Factors and Ergonomics in Manufacturing \& Service Industries, DOI: 10.1002/hfm.20272 (2011).

168. Shih, B. Y. and Li, C. E., "The exploration of mobile mandarin learning system by the application of triz theory," Computer Applications in Engineering Education, DOI: 10.1002/cae.20478 (2011).

169. Shih, B. Y. and Lo, T. W., "The research of quadtree search algorithms for anti-collision in radio frequency identification systems," Scientific Research and Essays, Vol. 6, No. 25, pp. $5342-5350$ (2011).

170. Shih, B. Y., Shih, C. H., Li, C. C., Chen, T. H., and Chen, Y. H., "Elementary school student's acceptance of Lego nxt: the technology acceptance model, a preliminary investigation," International Journal of the Physical Sciences, Vol. 6, No. 22, pp. 5054-5063 (2011).

171. Shih, B. Y., Shih, C. H., and Tseng, J. Y., "The development of enhancing mechanisms for improving the performance of ieee 802.15.4," International Journal of the Physical Sciences, Vol. 5, pp. $884-897$ (2010).

172. Shih, C. H., Wakabayashi, N., and Yamamura, S., "A context model with a time-dependent multi-layer exception handling policy," International Journal of Innovative Computing, Information and Control, Vol. 7, No. 5A, pp. 2225-2234 (2011).

173. Shih, C. H. and Yamamura, S., "Analysis of control structure for turning maneuvers," Mathematical Problems in Engineering, DOI: 10.1155/2010/481438 (2010).

174. Solihin, M. I., Wahyudi, and Legowo, A., "Fuzzy-tuned pid anti-swing control of automatic gantry crane," Journal of Vibration and Control, Vol. 16, No. 1, pp. 127-145 (2010).

175. Soundarrajan, A. and Sumathi, S., "Fuzzy-based intelligent controller for power generating systems," Journal of Vibration and Control, Vol. 17, No. 8, pp. 1265-1278 (2011).

176. Su, T. J., Cheng, J. C., Huang, M. Y., Lin, T. H., and Chen, C. W., “Applications of cellular neural networks to noise cancellation in gray images based on adaptive particle swarm optimization," Circuits, Systems, and Signal Processing, DOI: 10.1007/s00034-011-9269-x (2012).

177. Tang, J. P., Chiou, D. J., Chen, C. W., Chiang, W. L., Hsu, W. K., and Liu, T. Y., "A case study of damage detection in benchmark buildings using a hilbert-huang transform-based method," Journal of Vibration and Control, Vol. 17, No. 4, pp. 623-636 (2011).

178. Teo, K. L. and Lim, C. C., "Time-optimal control computation with application to ship steering," Journal of Optimization Theory and Applications, Vol. 56, No. 1, pp. 145-156 (1988).

179. Tsai, C. H. and Chen, C. W., "Development of a mechanism for typhoon and flood risk assessment and disaster management in the hotel industry - a case study of the Hualien area," Scandinavian Journal of Hospitality and Tourism, Vol. 11, No. 3, pp. 324-341 (2011).

180. Tsai, C. H. and Chen, C. W., "The establishment of a rapid natural disaster risk assessment model for the tourism industry," Tourism Management, Vol. 32, No. 1, pp. 158-171 (2011).

181. Tsai, C. H., Chen, C. W., Chiang, W. L., and Lin, M. L., "Application of geographic information system to the allocation of disaster shelters via fuzzy models," Engineering Computations-International Journal for Computer-Aided Engineering and Software, Vol. 25, pp. 86-100 (2008).

182. Tseng, C. P., Chang, M. L., and Chen, C. W., "The human factors of knowledge sharing intention among Taiwanese enterprises: a preliminary study," Human Factors and Ergonomics in Manufacturing \& Service Industries, DOI: 10.1002/hfm.20284 (2012).

183. Tseng, C. P. and Chen, C. W., "Natural disaster management mechanisms for probabilistic earthquake loss," Natural Hazards, DOI: 10.1007/s11069-011-9889-2 (2012).

184. Tseng, C. P., Chen, C. W., and Liu, F. R., "Risk control allocation model for pressure vessels and piping project," Journal of Vibration and Control, DOI: 10.1177/1077546311403182 (2012).

185. Tseng, C. P., Chen, C. W., and Tu, Y. P., “A new viewpoint on risk control decision models for natural disasters," Natural Hazards, DOI: 10.1007/s11069-011-9861-1 (2012).

186. Tu, J. W., Qu, W. L., and Chen, J., "An experimental study on semiactive seismic response control of a large-span building on top of ship lift towers," Journal of Vibration and Control, Vol. 14, No. 7, pp. 1055-1074 (2009).

187. Tusset, A. M., Rafikov, M., and Balthazar, J. M., “An intelligent controller design for magnetorheological damper based on a quarter-car model," Journal of Vibration and Control, Vol. 15, No. 12, pp. 19071920 (2009).

188. Tzeng, C. Y., "An internal model control approach to the design of yaw-rate-control ship-steering autopilot," Journal of Oceanic Engineering, Vol. 24, No. 4, pp. 507-513 (1999).

189. Tzeng, C. Y., "Optimal control of a ship for a course-changing maneuver," Journal of Optimization Theory and Applications, Vol. 97, No. 2, pp. 281-297 (1998).

190. Vanamerongen, J., Vanderklugt, P. G. M., and Lemke, H. R. V., "Rudder roll stabilization for ships," Automatica, Vol. 26, No. 4, pp. 679-690 (1991).

191. Velagic, J., Vukic, Z., and Omerdic, E., "Adaptive fuzzy ship autopilot for track-keeping," Control Engineering Practice, Vol. 11, No. 4, pp. 433-443 (2003).

192. Yang, H. C., Chen, C. W., and Chen, T. H., "Estimation on internal wave reflection in a two-layer fluid system by cumulative logistic regression model," Journal of Marine Science and Technology, Vol. 16, pp. 44-51 (2008).

193. Yang, H. C., Chen, T. H., Chen, C. W., and Liu, C. T., "Accuracy evaluation of a diagnostic test by detecting outliers and influential observations," China Ocean Engineering, Vol. 22, pp. 421-429 (2008).

194. Yavin, Y., Francos, C., and Miloh, T., "Computation of feasible control trajectories for the navigation of a ship around an obstacle in the presence of a sea current," Mathematical and Computer Modeling, Vol. 21, No. 3, pp. 99- 117 (1995).

195. Yavin, Y., Francos, C., Miloh, T., and Zilman, G., "Collision avoidance by a ship with a moving obstacle: computation of feasible command strategies," Journal of Optimization Theory and Applications, Vol. 93, No. 1, pp. 53-66 (1997).

196. Yavin, Y. and Miloh, T., "On the control and guidance of the motion of an immersed body: some problems in stochastic control," Journal of $O p$ timization Theory and Applications, Vol. 77, No. 3, pp. 613-641 (1993).

197. Yeghnem, R., Meftah, S. A., Tounsi, A., and Adda-Bedia, E., "Earthquake response of rc coupled shear walls strengthened with thin composite plates," Journal of Vibration and Control, Vol. 15, No. 7, pp. 963-984 (2009).

198. Yeh, K. and Chen, C. W., "Robustness design of time-delay fuzzy systems using fuzzy lyapunov method," Applied Mathematics and Computation, Vol. 205, pp. 568-577 (2008).

199. Yeh, K. and Chen, C. W., "Stability analysis of interconnected fuzzy systems using the fuzzy lyapunov method," Mathematical Problems in Engineering, Article Number: 734340 (2010).

200. Yeh, K., Chen, C. W., Lo, D. C., and Liu, K. F. R., "Neural-network fuzzy control for chaotic tuned mass damper systems with time delays," Journal of Vibration and Control, DOI: 10.1177/1077546311407538 (2012).

201. Yi, S., Nelson, P. W., and Ulsoy, A. G., "Eigenvalue assignment via the lambert w function for control of time-delay systems," Journal of Vibration and Control, Vol. 16, No. 7-8, pp. 961-982 (2010).

202. Yiming, F., Sheng, L., and Yejie, J., "Nonlinear active vibration control of piezoelastic laminated plates considering interfacial damage effects," Journal of Vibration and Control, Vol. 16, No. 9, pp. 1287-1320 (2010).

203. Yokoyama, M., Kim, G. N., and Tsuchiya, M., "Integral sliding mode control with anti-windup compensation and its application to a power assist system," Journal of Vibration and Control, Vol. 16, No.4, pp. 
503-512 (2010).

204. Yoo, S., Park, C. G., Lim, B., Lee, K. I., and Park, F. C., "Bandwidth maximizing design for hydraulically actuated excavators," Journal of Vibration and Control, Vol. 16, No. 14, pp. 2109-2130 (2010).

205. Yoshimura, T., "Adaptive discrete sliding mode control for mechanical systems with mismatched uncertainties," Journal of Vibration and Control, Vol. 16, No. 10, pp. 1417-1437 (2010).

206. Yoshimura, T., "Discrete-time adaptive sliding mode control for a class of uncertain time delay systems," Journal of Vibration and Control, Vol. 17, No. 7, pp. 1009-1020 (2011).

207. Yousefi, S. A., Lotfi, A., and Dehghan, M., "The use of a egendre multiwavelet collocation method for solving the fractional optimal control problems," Journal of Vibration and Control, Vol. 17, No. 13, pp. 2059 2065 (2011).

208. Yu, C. B., Wang, J. J., and Li, Q. H., "Investigation of the combined effects of intentional mistuning, damping and coupling on the forced response of bladed disks," Journal of Vibration and Control, Vol. 17, No. 8, pp. 1149-1157 (2011)

209. Yu, S. E., Li, M. Y. L., Huarng, K. H., and Chen, T. H., "Model construction of option pricing based on fuzzy theory," Journal of Marine Science and Technology, Vol. 19, No. 5, pp. 460-469 (2011).

210. Yu, S. E. S., Huarng, K. H., and Li, M. Y. L., "A novel option pricing model via fuzzy binomial decision tree," International Journal of Innovative Computing, Information and Control, Vol. 7, No. 2, pp. 709718 (2011).

211. Zhang, B., Billings, S. A., Lang, Z. Q., and Tomlinson, G. R., "Suppressing resonant vibrations using nonlinear springs and dampers," Journal of Vibration and Control, Vol. 15, No. 11, pp. 1731-1744 (2009).

212. Zhang, F., Grigoriadis, K. M., and Fialho, I. J., "Linear parametervarying control for active vibration isolation systems with stiffness hysteresis," Journal of Vibration and Control, Vol. 15, No. 4, pp. 527 547 (2009).

213. Zhang, $\mathrm{H}$. and $\mathrm{Ni}$, J., "Internal energy based analysis on mechanism of spindle speed variation for regenerative chatter control," Journal of Vibration and Control, Vol. 16, No. 2, pp. 281-301 (2010).

214. Zhang, H., Xie, X., and Zhao, J. L., "Parametric vibration of carbon fiber reinforced plastic cables with damping effects in long-span cable-stayed bridges," Journal of Vibration and Control, Vol. 17, No. 14, pp. 2117 2130 (2011).

215. Zhang, L. and Dupuis, R., "Measurement and identification of dynamic properties of flexible polyurethane foam," Journal of Vibration and Control, Vol. 17, No. 4, pp. 517-526 (2011).

216. Zhang, X., Mills, J. K., and Cleghorn, W. L., "Experimental implementation on vibration mode control of a moving 3-prr flexible parallel manipulator with multiple PZT transducers," Journal of Vibration and Control, Vol. 16, No. 13, pp. 2035-2054 (2010)

217. Zhang, Y., Huang, X., and Zhao, Q., "Sensitivity analysis for vibration transfer path systems with non-viscous damping," Journal of Vibration and Control, Vol. 17, No. 7, pp. 1042-1048 (2011).

218. Zhang, Y. and Sharf, I., "Force reconstruction for low velocity impacts using force and acceleration measurements," Journal of Vibration and Control, Vol. 17, No. 3, pp. 407-420 (2011).

219. Zhao, F., Chen, J., Guo, L., and Li, X., "Neuro-fuzzy based condition prediction of bearing health," Journal of Vibration and Control, Vol. 15 No. 7, pp. 1079-1091 (2009).

220. Zhao, F. G., Chen, J., Guo, L., and Li, X., "Neuro-fuzzy based condition prediction of bearing health," Journal of Vibration and Control, Vol. 15, No. 7, pp. 1079-1091 (2009).

221. Zhao, H. and Rahn, C. D., "Repetitive learning control of a flexible whisker in tip contact with an unknown surface," Journal of Vibration and Control, Vol. 17, No. 2, pp. 197-203 (2011).

222. Zhao, M. and Shen, X., "Effect of the seal force on nonlinear dynamics and stability of the rotor-bearing-seal system," Journal of Vibration and Control, Vol. 15, No. 2, pp. 197-217 (2009).

223. Zhao, M. and Zhu, W. Q., "Stochastic optimal semi-active control of stay cables by using magneto-rheological damper," Journal of Vibration and Control, Vol. 17, No. 13, pp. 1921-1929 (2011).

224. Zhao, Y., "Vibration suppression of a quadrilateral plate using hybrid piezoelectric circuits," Journal of Vibration and Control, Vol. 16, No. 5, pp. 701-720 (2010).

225. Zhao, Y., Zhao, L., and Gao, H., "Vibration control of seat suspension using h $\infty$ reliable control," Journal of Vibration and Control, Vol. 16, No. 12, pp. 1859-1879 (2010).

226. Zheng, L. A., Chen, S. H., Ho, W. H., and Chou, J. H., "Robust-optimal active vibration controllers design of flexible mechanical systems via orthogonal function approach and genetic algorithm," Journal of Vibration and Control, Vol. 17, No. 2, pp. 223-234 (2011).

227. Zheng, S. T., Ye, Z. M., Huang, Q. T., Cong, D. C., and Han, J. W., "Adaptive inverse control of time waveform replication for electrohydraulic shaking table," Journal of Vibration and Control, Vol. 17, No. 11, pp. 1611-1633 (2011).

228. Zhu, B., Gu, X., Du, D., and Peng, D., "Sound radiation modes of mdof waveguide suppressor in outer fluid," Journal of Vibration and Control, Vol. 15, No. 2, pp. 183-195 (2009).

229. Zhu, J., Mottershead, J. E., and Kyprianou, A., "An inverse method to assign receptances by using classical vibration absorbers," Journal of Vibration and Control, Vol. 15, No. 1, pp. 53-84 (2009).

230. Zhu, J., Ye, G. R., Xiang, Y. Q., and Chen, W. Q., “Dynamic behavior of cable-stayed beam with localized damage," Journal of Vibration and Control, Vol. 17, No. 7, pp. 1080-1089 (2011).

231. Zhu, W. Q. and Huan, R. H., "Stochastic optimal control of quasi integrable hamiltonian systems subject to actuator saturation," Journal of Vibration and Control, Vol. 15, No. 1, pp. 85-99 (2009). 